\title{
Predicting and Preventing Cardiovascular Risk in Patients with Diabetes
}

\author{
a report by
}

\author{
Paul Valensi, MD
}

Head, Department of Endocrinology-Diabetology-Nutrition, Jean Verdier Hospital

The cardiovascular (CV) risk in patients with diabetes is estimated to be two or three times higher than in the non-diabetic population. The prognosis of patients with diabetes following myocardial infarction (MI) remains poorer in comparison with non-diabetics. Besides traditional risk factors, some factors related to diabetes, including blood glucose control, are responsible for the acceleration of vascular disease.

\section{How to Evaluate the Cardiovascular Risk in}

\section{Patients with Diabetes?}

Coronary mortality has been suggested to be as high in diabetic patients without coronary disease as in non-diabetic patients with coronary disease, which led some authors to consider diabetes as a 'coronary equivalent.' This has been shown in a Finnish and a North American register. ${ }^{1-3}$ Data coming from the autopsic register of Rochester are in line with this assessment since, in the group of people over 65 who died, the prevalence rates of high-grade coronary lesions and multiple coronary lesions were as high in diabetic patients without antemortem coronary disease as in non-diabetic patients with antemortem coronary disease. ${ }^{4}$

However, contradictory data have been reported. In particular, in a Scottish cohort including patients with recently diagnosed type 2 diabetes and non-diabetic patients just after the onset of an $\mathrm{Ml}$, the survival rate was markedly better in the first group. ${ }^{5}$ In fact, CV risk correlates with diabetes duration as shown in the Health Care Professionals Studies in the US. ${ }^{6,7}$

In the UK Prospective Diabetes Study (UKPDS), the incidence of $\mathrm{Ml}$ correlated with age and several potentially modifiable CV risk factors: age, blood pressure, and low-density lipoprotein-cholestrol (LDL-C) levels, tobacco consumption, and mean glycated hemoglobin $\left(\mathrm{HbA}_{1 \mathrm{c}}\right)$ levels at follow-up, with a protective influence of high-density lipoprotein-cholestrol (HDL-C) levels. ${ }^{8}$ Nephropathy, even at the stage of microalbuminuria, is associated with an increased $\mathrm{CV}$ risk, ${ }^{9}$ particularly in patients with persistent microalbuminuria. ${ }^{10}$

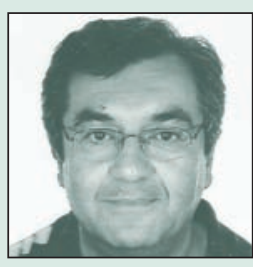

Paul Valensi, MD, is Head of the Department of EndocrinologyDiabetology-Nutrition at the Jean Verdier Hospital and Director of the Laboratory of Nutrition, Metabolic Diseases, and Cardiovascular Prevention at Paris-Nord University. Professor Valensi was Chairman of Neurodiab, the European Association for the Study of Diabetes (EASD) Study Group on Diabetic Neuropathy (2003-2006). He has authored approximately 180 articles and 30 book chapters.
All these factors should be taken into account when evaluating the CV risk in diabetic patients. Another way to assess this risk may be based on the detection of silent myocardial ischemia (SMI), in particular in patients over 60 years of age or after 10 years of type 2 diabetes. ${ }^{11}$ Indeed, the prevalence rate of SMI is very high-around $30 \%$-in diabetic patients with two or three other CV risk factors. SMI can be considered as an integrator of the overall risk. This is supported by the demonstration that SMI is a potent
Besides traditional risk factors, some
factors related to diabetes, including
blood glucose control, are responsible for
the acceleration of vascular disease.

predictor of CV events with a two- or three-fold higher event incidence in comparison with patients free of SMI. ${ }^{12,13}$ The risk related to SMI seems to be increased even in the patients with cardiac autonomic neuropathy assessed on abnormal heart rate variations. ${ }^{14}$

How to Prevent Cardiovascular Complications in Patients with Diabetes?

The prognosis of patients with diabetes following $\mathrm{Ml}$ can be markedly improved if coronary revascularization is used when possible in non-diabetic patients. ${ }^{15}$ Statin treatment should also be prescribed in diabetic patients with coronary disease, and the Treating New Targets (TNT) study has shown that the cardiac prognosis is improved when LDL-C levels are reduced to $70 \mathrm{mg} / \mathrm{dl}$ instead of $100 \mathrm{mg} / \mathrm{dl} .{ }^{16}$

A number of studies have shown that the prognosis post-MI is related to blood glucose levels. ${ }^{17,18}$ Experimental findings show in favor of the deleterious role of blood glucose on the arteries. ${ }^{19}$ This highlights the importance of improving blood glucose in these patients. The Diabetes Mellitus, Insulin Glucose Infusion in Acute Myocardial Infarction (DIGAMI) studies have confirmed that $\mathrm{HbA}_{1 \mathrm{c}}$ levels were significant and independent mortality predictors. The first DIGAMI trial supported the use of intensive insulin treatment after $\mathrm{Ml}$ in patients with diabetes..$^{20}$ These results were not confirmed by the DIGAMI 2 trial, which improved the first study's protocol and included more patients. ${ }^{21}$ The DIGAMI 2 trial suggests that type 2 diabetic patients should receive intensive glucose control after $\mathrm{MI}$, but that this can be achieved by alternative, and possibly more 
convenient, treatments than insulin. Therefore, in practice, antidiabetic treatment after $\mathrm{Ml}$ can consist of insulin or other hypoglycemic agents. However, insulin treatment is often necessary due to poor or unstable glycemic control, and to contraindications associated with some oral agents. The PROspective pioglitAzone Clinical Trial In macroVascular Events (PROactive) trial tested pioglitazone in addition to conventional therapy in patients with type 2 diabetes and CV disease. All-cause mortality, non-fatal $\mathrm{MI}$, and stroke were reduced, but the incidence of heart failure was increased. ${ }^{22}$ Therefore, glitazones may not be recommended for use during acute coronary syndromes.

In primary prevention, some trials suggest that blood glucose control may reduce $\mathrm{CV}$ risk. In the UKPDS, a $0.9 \% \mathrm{HbA}_{1 \mathrm{c}}$ reduction was associated with a $16 \%$ reduction of $\mathrm{MI}$ incidence with a borderline significance. ${ }^{23}$ In type 1 diabetes, the Epidemiology of Diabetes Interventions and Complications (EDIC) extension of the Diabetes Control and Complications Trial (DCCT) strongly endorses early intensive bloodglucose control with an insulin regimen consisting of multiple injections or

Cardiovascular risk should be assessed

in all patients with diabetes. Those

with a high risk should be treated

intensively, and this needs to be clearly

explained by their doctors in order to

improve compliance.

continuous subcutaneous insulin infusion, which may reduce the occurrence of CV complications by $50 \%$ after long-term follow-up. ${ }^{24}$

As to lipid management, statins have been tested in several trials in primary prevention. According to a recent meta-analysis including around 25,000 patients with diabetes, a $1 \mathrm{mmol} / \mathrm{LDL}-\mathrm{C}$ reduction is associated with a $25 \%$ decrease in coronary events. ${ }^{25}$ When looking at these trials, it appears more benefit is brought by statins in patients with a high CV risk-as shown in the Heart Protection Study (HPS) - and a lower benefit in those with a low riskas in the Atorvastatin Study for Prevention of coronary heart disease Endpoints in Non insulin-dependent diabetes (ASPEN) study. ${ }^{26}$ In patients with type 2 diabetes and a low CV risk, fenofibrate has been tested in a controlled trial—the Fenofibrate Intervention and Event Lowering in Diabetes (FIELD) study. In the primary prevention cohort it can be calculated that a $0.45 \mathrm{mmol} / \mathrm{I}$ LDL-C reduction was associated with a $20 \%$ decrease in coronary events, which might result from other beneficial effects of fenofibrate on lipid metabolism and inflammation process. ${ }^{27}$ These data suggest that type 2 diabetic patients should be treated by statins if the risk is high, and by statins or fenofibrate according to the lipid profile when the risk is low. ${ }^{26}$ In the FIELD study, the combination of statins with fenofibrate was safe. This combination can be used in some patients to lower LDL-C levels to $100 \mathrm{mg} / \mathrm{dl}$ and normalize triglyceride levels.

Regarding blood pressure control, the UKPDS has clearly shown that blood pressure (BP) reduction significantly decreases the incidence of stroke and microvascular complications. ${ }^{28}$ More recent studies have provided evidence for a higher benefit from the renin-angiotensin-system blockers than from other antihypertensive drugs in terms of cardio- and nephro-protection. In the Losartan Intervention For Endpoint (LIFE) trial, losartan has been tested versus atenolol and presents better CV mortality in patients with left ventricular hypertrophy. ${ }^{29}$

As for anti-aggregant treatments, they should be given to all diabetic patients with $\mathrm{CV}$ disease, and also to those in primary prevention and other $\mathrm{CV}$ risk factors.

The STENO-2 study (carried out by the Steno Diabetes Center) evaluated a plurifactorial approach in type 2 diabetic patients with a high CV risk. In the 'intensive group,' patients were treated in order to optimize blood glucose, $\mathrm{BP}$, and lipid controls; they received an angiotensin-converting enzyme inhibitor (ACE) or an angiotensin $\|$ receptor antagonist (ARA-2) and antiaggregants, and were given lifestyle advice. Convincing results were obtained, since the incidence of both CV events and microangiopathic complications was reduced by $50 \% .^{30}$

Finally, regarding SMI, some specific studies should be performed in order to clarify whether coronary revascularization in patients with significant coronary stenoses reduces cardiac outcomes.

In conclusion, CV risk should be assessed in all patients with diabetes. Those with a high risk should be treated intensively, and this needs to be clearly explained by their doctors in order to improve compliance.
1. Haffner $S M$, Lehto S, Ronnemaa T, et al., N Engl J Med 1998;339:229-34.

2. Juutilainen $A$, Lehto $S$, Ronnemaa $T$, et al., Diabetes Care, 2005:2:2901-7.

3. Mukamal KJ, Nesto RW, Cohen MC, et al., Diabetes Care, 2001;24:1422-7.

4. Goraya TY, Leibson CL, Palumbo PJ, et al., JACC, 2002;40:936-53.

5. Evans JM, Wang J, Morris AD, Br Med J, 2002;324:939-42.

6. Hu FB, Stampfer MJ, Solomon CG, et al., Arch Intern Med, 2001;161:1717-23.

7. Cho E, Rimm EB, Stampfer MJ, et al., I Am Coll Cardiol, 2002;40:954-60.

8. Turner RC, Millns $\mathrm{H}$, Neil HA, et al., Br Med J, 1998;316:823-8.

9. Miettinen $\mathrm{H}$, Haffner $\mathrm{SM}$, Lehto $\mathrm{S}$, et al., Stroke, 1996;27:2033-9.

10. Ibsen $\mathrm{H}$, Olsen MH, Wachtell $\mathrm{K}$, et al., Hypertension, 2005;45: 198-202.
11. Puel J, Valensi P, Vanzetto G, et al., Diabetes Metab, 2004;30:353-18.

12. Valensi $P$, Pariès J, Brulport-Cerisier $V$, et al., Diabetes Metab, 2005;28:2722-7.

13. Cosson E, Paycha F, Pariès J, et al., Diabet Med, 2004;21:342-8.

14. Valensi P, Johnson NB, Maison-Blanche P, et al., Diabetes Care, 2002;25:918-23.

15. Norhammar A, Malmberg K, Ryden L, et al., Eur Heart J, 2003;24:838-44.

16. Shepherd J, Barter $P$, Carmena $R$, et al., Diabetes Care, 2006;29:1220-26.

17. Malmberg K, Norhammar A, Wedel H, Ryden L, Circulation, 1999:99:2626-32.

18. Umpierrez GE, Isaacs SD, Bazargan $N$, et al., J Clin Endocrinol Metab, 2002;87:978-82.

19. Oliver MF, Opied LH, Lancet, 1994;343:155-8.

20. Malmberg K, Ryden L, Hamsten A, et al., Eur Heart J, 1996;1:1337-44.
21. Malmberg K, Ryden L, Wedel H, et al., Eur Heart J, 2005;26:650-61.

22. Dormandy JA, Charbonnel B, Eckland DJ, et al., Lancet, 2005;366:1279-89.

23. UK Prospective Diabetes Study (UKPDS) Group, Lancet, 1998;352(9131):837-53.

24. Nathan DM, Cleary PA, Backlund JY, et al., N Engl J Med, 2005;353(25):2643-53.

25. Baigent. C, Keech A, Kearney PM, et al., Lancet, 2005;366: 1267-78.

26. Valensi P, Chapman J, Atheroscler Thromb Vasc Biol, submitted.

27. Keech A, Simes RJ, Barter P, et al., Lancet, 2005;366:1849-61.

28. UK Prospective Diabetes Study (UKPDS) Group, Br Med J, 1998;317(7160):703-13.

29. Kieldsen $S E$, Dahlof $B$, Devereux RB, et al., JAMA, 2002;288: 1491-8.

30. Gaede P, Vedel P, Parving HH, Pedersen O, Lancet, 1999;353: 617-22. 